УДК 550.832

\title{
ОСОБЕННОСТИ ПЕТРОФИЗИЧЕСКИХ СВОЙСТВ СЛОЖНОПОСТРОЕННЫХ КАРБОНАТНЫХ ТОЛЩ ПО КОМПЛЕКСНЫМ ГЕОФИЗИЧЕСКИМ ДАННЫМ
}

\author{
Чучалина Кристина Юрьевна ${ }^{1}$, \\ K.Yu.Chuchalina@gmail.com
}

\author{
Коровин Михаил Олегович 1 , \\ korovinmo@hw.tpu.ru \\ 1 Национальный исследовательский Томский политехнический университет,
Россия, 634050, г. Томск, пр. Ленина, 30.
}

\begin{abstract}
Актуальность исследования определена необходимостью прогнозирования латеральной изменчивости литологических типов пород, что оказывает влияние на разработку и экономическую оценку месторождения. Очень часто нефтяные компании имеют ограниченный набор геолого-геофизической инфрормации, в связи с чем возникают трудности для прогнозирования перспективных областей, что способствует увеличению неопределенностей при изучении территории месторождения.

Цель: выделение и статистическое обоснование фрациального строения по данным геолого-геофизической информации на примере одного из месторождений Томской области, приуроченного к палеозойскому фундаменту Западной Сибири.

Объектом исследования являются отложения палеозойского фундамента юго-восточной части Западно-Сибирской плиты коллекторы сложнопостроенных карбонатных толщ, окно исследования, которое охватьвает объем горной породы, равный 40 м, выбрано исходя из условий построения сейсмофациальной карты.

Методы исследования основаны на использовании комплексного анализа данных - статистическое сопоставление геосризических исследований и кернового материала. Такой анализ способствует уменьшению неопределенностей в процессе оценки и прогноза геологической среды. В работе отмечено, что использование широкого спектра информации влияет на оценку и прогноз распределения геологических тел в пространстве. Предложена методика сравнения акустических свойств, полученных из первоначального источника - сейсмические данные, с расчетными акустическими свойствами по керновым данным. Выявлены взаимосвязи между сейсмической, геофизической инфрормацией и лабораторными исследованиями керна. Обоснование полученной сейсмофациальной карты на основе комплексирования данных позволяет эфффективно прогнозировать геологическое распределение фаций в пространстве и времени, но также уменьшать неопределенности при построении геологической модели.
\end{abstract}

\section{Ключевые слова:}

Фация, лабораторные исследования керна, акустический импеданс, комплексирование, палеозойские отложения.

\section{Введение}

Нередко геолого-геофизические данные имеют низкую информативность, что является следствием возникновения неопределенностей для прогноза формы, размера, расположения геологического тела, а также для выявления зон нефтегазонакоплений. Данные трудности возникают, например, из-за сложного строения территории или из-за разрешающей способности методов исследования. Эти условия характерны для исследуемого месторождения, которое представляет палеозойский стратиграфический диапазон нефтегазоносности - от среднего до позднего девона. В течение среднего и верхнего девона территория подвергалась активной разломной тектонике, что является причиной для формирования органогенного биогерма. Стоит отметить, что с северо-востока данный биогерм был ограничен открытым глубоководным бассейном, а с юго-запада - изолированным мелководным морем $[1,2]$. Принимая во внимание сложные геологические условия, необходимо комплексировать геолого-геофизическую информацию для повышения достоверности прогноза фациального строения изучаемой территории. Также стоит отметить, что совместное изучение и сопоставление геологической информации необходимо для рационального освоения месторождения.
Для анализа фациального строения изучаемого месторождения за основу была принята сейсмофациальная карта сложнопостроенных карбонатных толщ [3-5], которая была получена благодаря комплексу сейсмических атрибутов: мгновенная частота, мгновенная фаза, мгновенное качество, относительный акустический импеданс, первая производная, затухание [6-9].

\section{О методике петрофизического анализа}

Изучаемое нефтяное месторождение характеризуется невысоким процентом выноса керна, что вносит неопределенность при прогнозировании распределения фаций. Стоит отметить, что отбор керна был осуществлен только из двух эксплуатационных скважин № 1 и 2, где фонд скважин представлен четырьмя разведочными и девятью эксплуатационными скважинами. Согласно опубликованным данным [10], для нахождения корреляционной связи необходимо не менее 30 точек исследования, чтобы полученная зависимость являлась корректной. В данном случае количество образцов кернового материала в исследуемом интервале из двух скважин составляет 65 шт, данный факт является допустимым для дальнейших исследований.

Измерения упругих свойств на керне для сопоставления с сейсмической и геофизической информацией были проведены в скважинах № 1 и 2, наличие 
кернового материала увеличивает достоверность комплексирования ГИС-керн. Для предсказания фациальной обстановки было рассчитано акустическое свойство - акустический импеданс, по формуле, представленной ниже [11]:

$$
\mathrm{AI}=\mathrm{V}_{\mathrm{p}} * \mathrm{p},
$$

где AI - акустический импеданс м/ $\mathrm{c}^{*} / \mathrm{cm}^{3} ; \mathrm{V}_{\mathrm{p}}$ - скорость продольной волны м/c; p - плотность горной породы $г / \mathrm{cm}^{3}$.

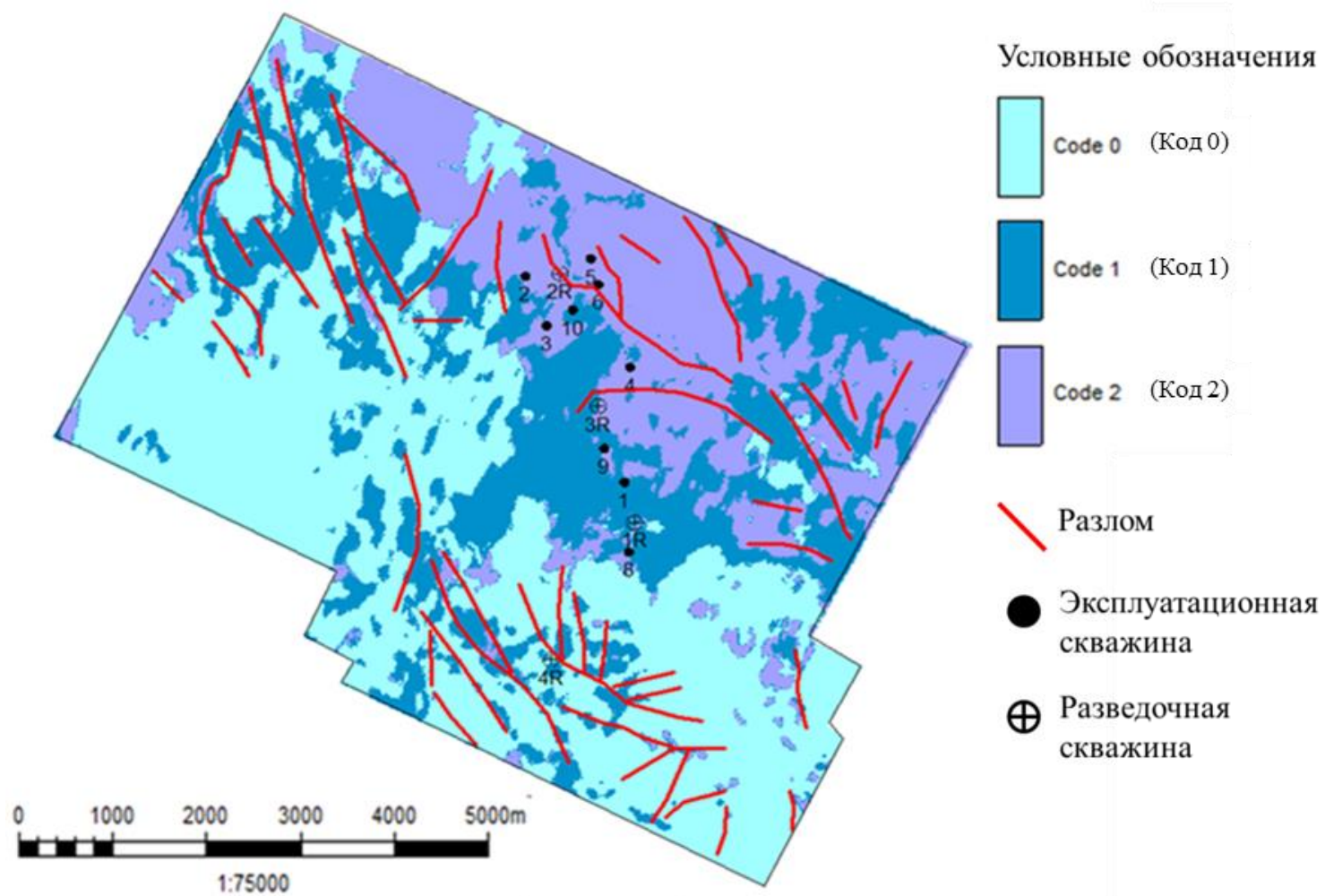

Pис. 1. Сейсмофациальная карта сложнопостроенных карбонатных толщ по кровле фундамента Ф2

Fig. 1. Seismic facies map of complex carbonate reservoir by the top of the basement F2

Из-за отсутствия измерений скорости продольной волны в эксплуатационной скважине № 1 невозможно рассчитать сейсмический параметр, поэтому была получена зависимость на основе данных скважины № 2 для восстановления упругого свойства породы (рис. 2).

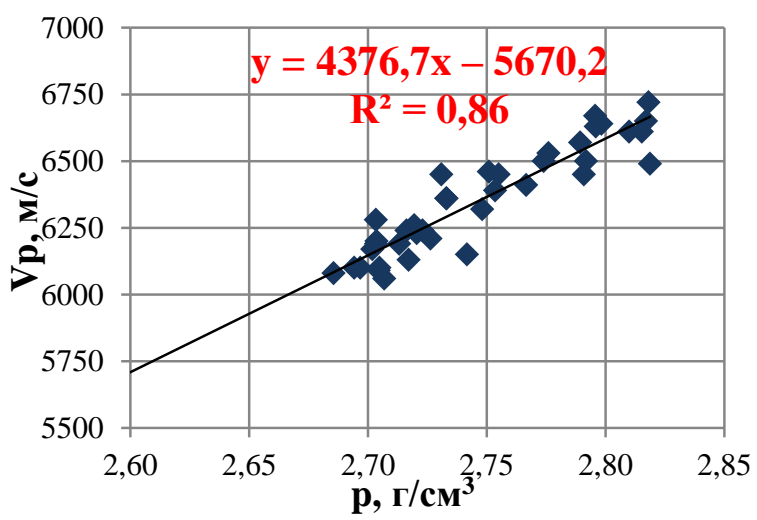

Pис. 2. Зависимость плотности горной породы и скорости продольной волны для скважины № 2

Fig. 2. Dependence of rock density and the velocity of the longitudinal wave for well no. 2

Полученный расчётный акустический импеданс по керновым данным двух эксплуатационных скважин был сопоставлен с частотой распределения акустического параметра по ГИС (геофизические исследования скважин) (рис. 3).

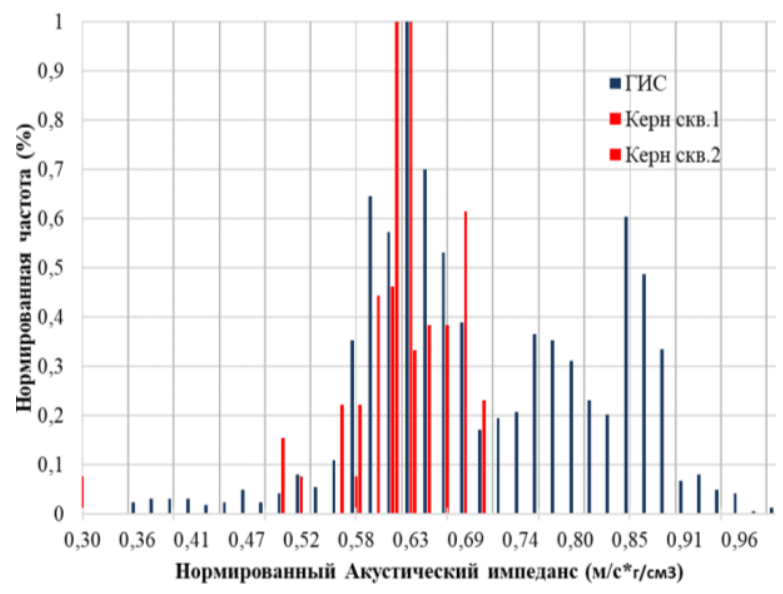

Pис. 3. Частота распределения акустического импеданса по данным лабораторных исследований керна и ГИС (геофизические исследования скважин) для скважин № 2, 2R, 10, 1, 1R и $3 R$

Fig. 3. Frequency of distribution of acoustic impedance according to laboratory tests of core and well logs for wells no. 2, $2 R, 10,1,1 R$ and $3 R$ 
По оси X показаны нормированные значения акустического импеданса, а по оси Ү отложена нормированная частота появления переменной (акустический импеданс по ГИС и керну), где вся площадь гистограммы принимается равной единице. Соответственно, самый высокий столбик на гистограмме характеризует интервал с наиболее вероятными результатами. Сопоставление скважинных данных позволяет выделить наиболее достоверные кластеры фаций, так как вероятность распределения в межскважинном пространстве определенного литотипа выше благодаря точечным исследованиям в скважине. Также необходимо отметить, что наличие связи в точке исследуемого интервала между образцом керна и геофизическими исследованиями скважин показывает досто- верность данных не только на качественном, но и на количественном уровне.

Исходя из анализа геофизических данных и лабораторных исследований керна для фонда скважин № 2, 2R, 10, 1, 1R и 3R, был сделан прогноз распределения фаций с более достоверной вероятностью в области расположения этих скважин. При помощи статистических данных было выявлено, что разведочные скважины № 2R и № 1R вскрывают в преобладающем объеме доломит, а три эксплуатационные скважины № 2, 10, 1 и одна разведочная скважина № 3R представлены известняком.

Согласно указанной кластеризации сейсмофациальной карты Цвет-Фация (рис. 1) была составлена сводная таблица для статистического обоснования (таблица) [12].

Таблица. Сводная таблица по данным сейсмической и геолого-геофизической информации

Table. Summary table according to seismic, geological and geophysical information

\begin{tabular}{|c|c|c|c|c|}
\hline $\begin{array}{c}\text { Тип исследования } \\
\text { Research type } \\
\text { Скважина № } \\
\text { Well no. } \\
\end{array}$ & $\begin{array}{l}\text { Kepн } \\
\text { Core }\end{array}$ & $\begin{array}{c}\text { ГИС } \\
\text { Well logs }\end{array}$ & $\begin{array}{l}\text { Сейсмофациальная карта } \\
\text { Seismic facies map }\end{array}$ & $\begin{array}{c}\text { Вероятность, \% } \\
\text { Probability, \% }\end{array}$ \\
\hline 5 & - & $\begin{array}{l}\text { Известняк } \\
\text { Limestone } \\
\end{array}$ & $\begin{array}{l}\text { Доломит } \\
\text { Dolomite } \\
\end{array}$ & 50 \\
\hline 6 & - & $\begin{array}{l}\text { Известняк } \\
\text { Limestone }\end{array}$ & $\begin{array}{l}\text { Доломит } \\
\text { Dolomite }\end{array}$ & 50 \\
\hline 2 & $\begin{array}{l}\text { Известняк } \\
\text { Limestone }\end{array}$ & $\begin{array}{l}\text { Известняк } \\
\text { Limestone }\end{array}$ & $\begin{array}{l}\text { Доломит } \\
\text { Dolomite } \\
\end{array}$ & 66,6 \\
\hline $2 \mathrm{R}$ & - & $\begin{array}{l}\text { Доломит } \\
\text { Dolomite }\end{array}$ & $\begin{array}{l}\text { Доломит } \\
\text { Dolomite }\end{array}$ & 100 \\
\hline 10 & - & $\begin{array}{l}\text { Известняк } \\
\text { Limestone }\end{array}$ & $\begin{array}{l}\text { Известняк } \\
\text { Limestone }\end{array}$ & 100 \\
\hline 1 & $\begin{array}{l}\text { Известняк } \\
\text { Limestone }\end{array}$ & $\begin{array}{l}\text { Известняк } \\
\text { Limestone } \\
\end{array}$ & $\begin{array}{l}\text { Известняк } \\
\text { Limestone }\end{array}$ & 100 \\
\hline $1 \mathrm{R}$ & - & $\begin{array}{l}\text { Доломит } \\
\text { Dolomite }\end{array}$ & $\begin{array}{l}\text { Известняк } \\
\text { Limestone }\end{array}$ & 50 \\
\hline 4 & - & $\begin{array}{l}\text { Известняк } \\
\text { Limestone } \\
\end{array}$ & $\begin{array}{l}\text { Доломит } \\
\text { Dolomite } \\
\end{array}$ & 50 \\
\hline $4 \mathrm{R}$ & $\begin{array}{c}\text { Глинисто-кремнистые } \\
\text { Argillaceous-siliceous }\end{array}$ & - & $\begin{array}{c}\text { Глинисто-кремнистые } \\
\text { Argillaceous-siliceous }\end{array}$ & 66,6 \\
\hline 3 & - & $\begin{array}{l}\text { Известняк } \\
\text { Limestone }\end{array}$ & $\begin{array}{l}\text { Доломит } \\
\text { Dolomite } \\
\end{array}$ & 50 \\
\hline $3 R$ & - & $\begin{array}{l}\text { Доломит } \\
\text { Dolomite } \\
\end{array}$ & $\begin{array}{l}\text { Известняк } \\
\text { Limestone }\end{array}$ & 50 \\
\hline 9 & - & $\begin{array}{l}\text { Известняк } \\
\text { Limestone }\end{array}$ & $\begin{array}{l}\text { Известняк } \\
\text { Limestone }\end{array}$ & 100 \\
\hline 8 & - & $\begin{array}{l}\text { Доломит } \\
\text { Dolomite } \\
\end{array}$ & $\begin{array}{l}\text { Известняк } \\
\text { Limestone }\end{array}$ & 50 \\
\hline
\end{tabular}

На основе проведенного комплексного анализа геолого-геофизических данных была установлена вероятность наличия определенной фации в области скважины, что приведено в таблице $[13,14]$. Скважины, которые характеризуются вероятностью встречаемости определенной фации более 50 \%, представляют наиболее достоверные области распространения данной фации. К такому фонду относятся скважины № 2, 2R, 10, $1,1 \mathrm{R}$ и 3R. Необходимо отметить, что скважина 3R представляет вероятность 50 \% распределения как доломита, так и известняка, но, исходя из данных ГИС и сейсмофациальной карты, было принято решение, что достоверность встречаемости фации доломит 100 \%, так как на сейсмической карте данная скважина расположена на границе фаций доломит-известняк.

При использовании комплексной интерпретации геологических данных появляется возможность сни- жения рисков и неопределенностей, связанных с разрешающей способностью, например, сопоставляя сейсмические данные со скважинной информацией, это позволяет увеличить область достоверности околоскважинного пространства [15]. На основе полученных результатов по статистическому анализу геолого-геофизической информации было построено распределение фаций по сейсмическому атрибуту относительный акустический импеданс только для скважин с достоверной фактической информацией, где каждой скважине присвоена определенная фация [16]. По оси X отложена переменная относительного акустического импеданса, а по оси Y - количество наблюдений, попадающих в соответствующий диапазон на оси Х. Исходя из частотного распределения параметра относительного акустического импеданса, представленного на рис. 4, где возникает неполное 
разделение между двумя фациями - доломит и известняк, были проанализированы исследуемые области около скважин (рис. 1) [17-19]. Стоит отметить, что скважина 1R расположена на границе разделения доломит-известняк, поэтому данная скважина не учитывалась при построении распределения значений по сейсмическому атрибуту (рис. 5).

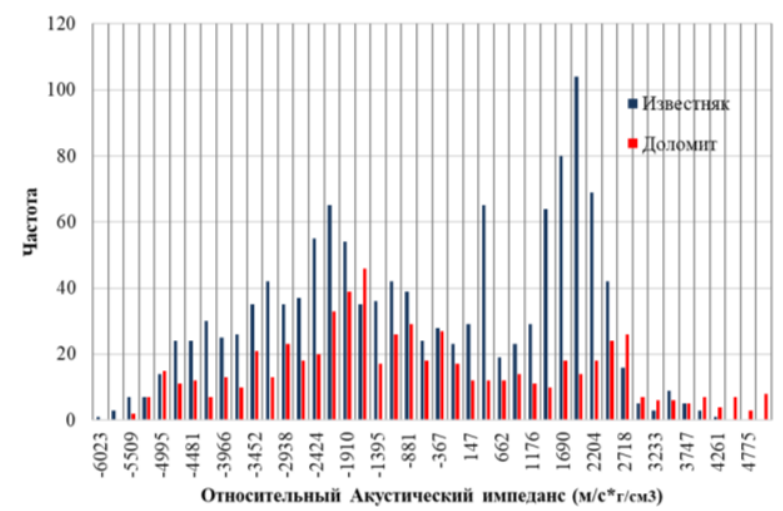

Pис. 4. Частота распределения переменной - относительный акустический импеданс

Fig. 4. Variable distribution frequency - relative acoustic impedance

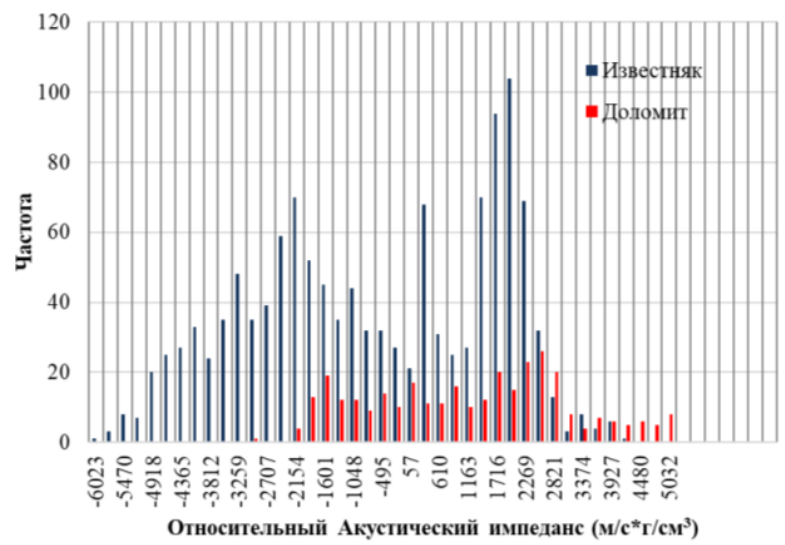

Рис. 5. Частота распределения переменной - относи тельный акустический импеданс без скважинь $1 R$

Fig. 5. Variable distribution frequency - relative acoustic impedance without well $1 R$

\section{СПИСОК ЛИТЕРАТУРЫ}

1. Ежова А.В. Изучение палеозойских коллекторов СевероОстанинского нефтяного месторождения по керну и шламу. Кн. 1. - Томск: Изд-во Томского политехнического университета, 2011. - 102 с

2. Ежова А.В., Меркулов В.П., Чеканцев В.А. Геологическая модель строения палеозойского фундамента СевероОстанинского нефтяного месторождения (Томская область) // Горный журнал. - 2012. - Специальный выпуск. - С. 35-38.

3. Волкова А.А. Комплексный анализ сейсмических и скважинных данных при изучении трещиноватых коллекторов на примере месторождения в фундаменте Западной Сибири // Проблемь геологии и освоения недр: Труды XXI Международного научного симпозиума имени академика М.А. Усова студентов и молодых ученых. - Томск: ТПУ, 2017. - Т. I. - С. 356-358.

4. Волкова А.А. Выбор оптимальных параметров сейсмического фациального анализа при изучении палеозойских отложений
Таким образом, имея площадное распределение фаций изучаемого объекта, полученное в результате анализа формы сейсмического сигнала, можно провести районирование территории, но восстановление обстановок осадконакопления и прогноз фаций необходимо проводить совместно с интерпретацией ГИС и лабораторными исследованиями керна, что подтверждается данными таблицы [20-22].

\section{Заключение}

В результате проведенных комплексных исследований геологической среды были изучены карбонатные отложения с позиции фациального строения. Предложенная авторами методика ясно отражает последовательность интерпретации геологической информации - сейсмика, геофизика, лабораторные исследования керна. Данный подход включает кластеризацию полученных результатов на основе сейсмического параметра - акустический импеданс.

На основе детальных литолого-фациальных исследований по комплексу упругих свойств в керне скважин и геофизических данных было детально изучено шесть скважин - № 2, 2R, 10, 1, 1R и 3R, на основе которых было выделено распределение фаций. Закономерности распределения фаций по латерали были установлены с помощью совместной интерпретации сейсмических, геофизических данных и лабораторных исследований керна.

Резюмируя все вышесказанное, имея минимальный спектр данных, но с хорошим качеством, можно осуществить интерпретацию на более достоверном уровне, то есть определить связи между керновым материалом и геофизическими данными, что в дальнейшем позволяет спроецировать полученную связь на сейсмический куб. Необходимо отметить, что, используя комплексирование результатов исследования, появляется вероятность уменьшения неопределенностей геологической среды. Данный факт в дальнейшем благоприятно влияет на проектирование геологических объектов. По результатам исследования были выявлены области соответствия между сейсмическими данными и геолого-геофизической интерпретацией, уточнены распределения фаций в межскважинном пространстве и выявлены области для перспективного бурения новых скважин.

Западной Сибири // Проблемы геологии и освоения недр: Труды XXII Международного научного симпозиума имени академика М.А. Усова студентов и молодых ученых. - Томск: ТПУ, 2018. - Т. I. - С. 383-384.

5. Волкова А.А. Применение сейсмофациального анализа для уточнения схемы геологического строения на примере место рождения в фундаменте Западной Сибири // Современные проблемы седиментологии в нефтегазовом инжиниринге: Труды III Всероссийского научно-практического седиментологического совещания. - Томск, 2017. - С. 223-228.

6. Seismic facies analysis and structural interpretation of the Sandakan sub-basin / K. Futalan, A. Mitchell, K. Amos, G. Backe // AAPG international conference and exhibition. - Singapore, 2012. URL: www.searchanddiscovery.com/documents/2012/30254futalan/ ndx_futalan.pdf (дата обращения 14.02.2021).

7. White R.E. Properties of instantaneous seismic attributes // The Leading Edge. -1991. - V. 10. - № 7. - P. 26-32. 
8. Interactive seismic facies classification using textural attributes and neural networks / B.P. West, S.R. May, J.E. Eastwood, C. Rossen // The Leading Edge. - 2002. - V. 21. - № 10. P. $1042-1049$.

9. Chopra S., Marfurt K. Seismic attributes for prospect identification and reservoir characterization // Geophysical developments. Tulsa: SEG, 2007. -464 p.

10. Методические рекомендации по подсчету геологических запасов нефти и газа объемным методом / под ред. В.И. Петерсильс, В.И. Пороскуна, Г.Г. Яценко. - М.; Тверь: ВНИГНИ, НПЦ «Тверьгеофизика», 2003. $-258 \mathrm{c}$.

11. Прогнозирование структуры и свойств природных резервуаров на основе комплексной интерпретации сейсмических и скважинных геолого-геофизических данных / А.П. Жуков, В.А. Жемчугова, К.А. Эпов, С.Л. Федотов // Технологии сейсморазведки. - 2006. - № 1. - С. 69-78.

12. Чучалина К.Ю. Статистическое обоснование сейсмофацильного анализа сложнопостроенных карбонатных коллекторов Северо-Останинского нефтяного месторождения: магистерская диссертация. - Томск, 2019. - 84 с.

13. Чоловский И.П. Методы геолого-промыслового анализа при разработке крупных нефтяных месторождений. - М.: Недра, 1966. $-180 \mathrm{c}$.

14. Чернова О.С., Захарова А.А. К вопросу о классификации обстановок осадконакопления, фаций, генетических типов пород и осадочных текстур с позиций кластерного анализа // Геологическое строение и нефтегазоносность отложений юговостока Западно-Сибирской плиты (Томская область). - Ново- сибирск: Изд-во Новосибирского государственного университета, 2006. - С. 175-178.

15. Amaefule J.O., Keelan D.K. Stochastic approach to computation of uncertainties in petrophysical properties // SCA conference. Texas, 1989. - P. 1-28.

16. Дэвис Дж. Статистический анализ данных в геологии. - М.: Недра, 1990. - С. 424-427.

17. Кузнецов В.Г. Фации и фациальный анализ в нефтегазовой геологии. - М.: ИЦ РГУ нефти и газа им. И.М. Губкина, 2012. $-244 \mathrm{c}$.

18. Слосс Л.А., Крумбейн В.К., Дэплз Э.В. Комплексный фациальный анализ // Осадочные фации в геологической истории. Л.; М.: Недра, 1953. - 289 с.

19. Хэллем Э. Интерпретация фаций и стратиграфическая последовательность. - М.: Мир, 1983. -328 с.

20. Olneva T., Ovechkina V., Zhukovskaya E. Object-oriented geoseismic analysis: ways and examples // XVII Serbian geological congress. Book of Abstracts. - Serbia, 2018. - P. 707-713.

21. Linari V. Seismic facies analysis based on 3D multiattribute volume classification, La Palma Field, Maracaibo, Venezuela / V. Linari, M. Santiago, C. Pastore, K. Azbel, M. Poupon // The Leading Edge. - 2003. - P. 32-36.

22. Davies D.K., Vessell R.K. Flow unit characterization of a shallow shelf carbonate reservoir: North Robinson Unit, West Texas // 10th Symposium on Improved Oil Recovery. - Tulsa, 1996. - P. 21-24.

Поступила 09.06.2021 2.

\section{Информация об авторах}

Чучалина К.Ю., магистрант Инженерной школы природных ресурсов Национального исследовательского Томского политехнического университета.

Коровин М.O., кандидат геолого-минералогических наук, доцент отделения нефтегазового дела Инженерной школы природных ресурсов Национального исследовательского Томского политехнического университета. 
UDC 550.832

\title{
SPECIFIC FEATURES OF PETROPHYSICAL PROPERTIES OF COMPLEX CARBONATE RESERVOIR BY COMPLEX GEOPHYSICAL DATA
}

\author{
Kristina Yu. Chuchalina1, \\ K.Yu.Chuchalina@gmail.com \\ Mikhail O. Korovin ${ }^{1}$, \\ korovinmo@hw.tpu.ru \\ 1 National Research Tomsk Polytechnic University, \\ 30, Lenin avenue, Tomsk, 634050, Russia.
}

\begin{abstract}
The relevance of the research is determined by the need to predict the lateral variability of lithological rock types, which affects the development and economic evaluation of the field. Very often, oil companies have a limited set of geological and geophysical information, in this relation the difficulties arise in predicting promising areas, which contributes to increase in uncertainties in the study of the field.

The main aim of the research is isolation and statistical justification of the facies structure according to the geological and geophysical information on the example of one of the deposits of the Tomsk region, confined to the Paleozoic basement of Western Siberia.

The object of the study is deposits of the Paleozoic basement of the southeastern part of the West Siberian Plate - complex carbonate reservoir, the study window that covers a rock volume of $40 \mathrm{~m}$ is selected based on the conditions for constructing a seismic facies map. Methods of the research are based on the use of integrated data analysis - a statistical comparison of geophysical surveys and core material. This analysis helps to reduce uncertainties in the process of assessing and forecasting the geological environment. The paper notes that the use of a wide range of information affects the assessment and forecast of the distribution of geological bodies in space. A technique is proposed for comparing acoustic properties obtained from the original source - seismic data, with the calculated acoustic properties from core data. The authors have revealed the interconnections between seismic, geophysical information and core research. The justification of the obtained seismic facies map based on the data integration allows us to effectively predict the geological distribution of facies in space and time, but also to reduce uncertainties in the construction of the geological model.
\end{abstract}

\section{Key words:}

Facies, laboratory-based core analysis, acoustic impedance, fusion, paleozoic deposits.

\section{REFERENCES}

1. Ezhova A.V. Izuchenie paleozoiskikh kollektorov SeveroOstaninskogo neftyanogo mestorozhdeniya po kernu i shlamu [Study of Paleozoic reservoirs of the North Ostaninskoe oil field by core and sludge]. B. 1. Tomsk, TPU Publ. house, 2011. 102 p.

2. Ezhova A.V., Merkulov V.P., Chekantsev V.A. Geologicheskay model stoeniya paleozoiskogo fundamenta Severo-Ostaninskogo neftyanogo mestorojdenya (Tomskay oblast) [Paleozoic basement geological structure model of Northern Ostaninskoe oil field (Tomsk region)]. Mountain Journal, 2012, Special issue, pp. 35-38.

3. Volkova A.A. Vybor optimalnykh parametrov seysmicheskogo fatsialnogo analiza pri izuchenii paleozoiskikh otlozheniy Zapadnoy Sibiri [Selection of optimal parameters of seismic facies analysis in the study of Paleozoic deposits in Western Siberia]. Problemy geologii $i$ osvoeniya nedr. Trudi XXII Mezhdunarodnogo nauchnogo simpoziuma imeni akademika M.A. Usova studentov $i$ molodykh uchenykh [Problems of geology and subsoil development. Proc. of the XXII International Scientific Symposium named after academician M.A. Usov for students and young scientists]. Tomsk, TPU Publ. house, 2018. Vol. I, pp. 383-384.

4. Volkova A.A. Kompleksniy analiz seismicheskikh i skvazhinnykh dannykh pri izuchenii treshchinovatykh kollektorov na primere mestorozhdeniya $\mathrm{v}$ fundamente Zapadnoy Sibiri [Comprehensive analysis of seismic and well data in the study of fractured reservoirs on the example of a field in the basement of Western Siberia] Problemy geologii i osvoeniya nedr. Trudi XXII Mezhdunarodnogo nauchnogo simpoziuma imeni akademika M.A. Usova studentov i molodykh uchenykh [Problems of geology and subsoil development. Proc. of the XXI International Scientific Symposium named after academician M.A. Usov for students and young scientists]. Tomsk, TPU Publ. house, 2018. Vol. I, pp. 356-358.

5. Volkova A.A. Primenenie seismofatsialnogo analiza dlya utochneniya skhemy geologicheskogo stroeniya na primere mestorozgdeniya $v$ fundamente Zanadnoy Sibiri [Use of seismic facies analysis to clarify the geological structure of the field as an example in the basement of Western Siberia]. Sovremennye problemy sedimentologii $v$ neftegazovom inzhiniringe. Trudy III vse rossiyskogo nauchno prakticheskogo sedimentilogicheskogo soveshchaniya [Modern problems of sedimentology in oil and gas engineering. Proc. of the III All-Russian Scientific and Practical Sedimentology Meeting]. Tomsk, 2017. pp. 223-228.

6. Futalan K., Mitchell A., Amos K., Backe G. Seismic facies analysis and structural interpretation of the Sandakan sub-basin. $A A P G$ international conference and exhibition. Singapore, 2012. Available at: www.searchanddiscovery.com/documents/2012/30254futalan/ ndx_futalan.pdf (accessed 14 February 2021).

7. White R.E. Properties of instantaneous seismic attributes. The Leading Edge, 1991, vol. 10, no 7, pp. 26-32.

8. West B.P., May S.R., Eastwood J.E., Rossen C. Interactive seismic facies classification using textural attributes and neural networks. The Leading Edge, 2002, vol. 21, no. 10, pp. 1042-1049.

9. Chopra S., Marfurt K. Seismic attributes for prospect identification and reservoir characterization. Geophysical developments. Tulsa, SEG, 2007. $464 \mathrm{p}$

10. Metodicheskie rekomendatsii po podschetu geologicheskikh zapasov nefti i gaza obemnym metodom [Guidelines for calculating the geological reserves of oil and gas by the volumetric method]. Eds. V.I. Petersils, V.I. Poroskuna, G.G. Yatsenko. Moscow, Tver, VNIGNI, Scientific and Practical Center «Tvergeofizika», 2003. $258 \mathrm{p}$

11. Zhukov A.P., Zhemchugova V.A., Epov K.A., Fedotov S.L. Prognozirovanie structury i svoystv prirodnyh rezervuarov na osnove kompleksnoy interpretacii seismicheskih i skvaginyh geologo-geofizicheskih dannyh [Prediction of the structure and properties of natural reservoirs based on a comprehensive interpretation of seismic and borehole geological and geophysical data]. Seismic exploration technologies, 2006, no 1, pp. 69-78.

12. Chuchalina K.Yu. Statisticheskoe obosnovanie seismofatsialnogo analiza slozhnopostroennykh carbonatnykh kollektorov SeveroOstaninskogo neftynogo mestorozhdeniya: magisterskay dissertatsiya [Statistical justification of seismic facies analysis of complex carbonate reservoirs of the North-Ostaninskoye oil field: master's thesis]. Tomsk, 2019. $84 \mathrm{p}$.

13. Cholovsky I.P. Metody geologo-promyslovogo analiza pri razrabotke krupnykh neftynykh mestorozhdeniy [Methods of geologi- 
cal field analysis in the development of large oil fields]. Moscow, Nedra Publ., 1966. 180 p.

14. Chernova O.S., Zakharova A.A. K voprosy o klassifikatsii obstanovok osadkonakopleniy, fatsii, geneticheskikh tipov porod i osadochnykh tekstur s pozitsii klasternogo analiza [On the classification of sedimentation conditions, facies, genetic types of rocks and sedimentary textures from the perspective of cluster analysis]. Geologicheskoe stroenie $i$ neftegazonosnost otlozheny yugovostoka Zapadno-Sibirskoy plity (Tomskaya oblast) [Geological structure and oil and gas content of sediments in the southeast of the West Siberian Plate (Tomsk Region)]. Novosibirsk, NGU Publ. house, 2006. pp. 175-178.

15. Amaefule J.O., Keelan D.K. Stochastic approach to computation of uncertainties in petrophysical properties. SCA conference. Texas, 1989. pp. 1-28.

16. Davis J. Statisticheskii analiz dannykh v geologii [Statistical analysis of data in geology]. Moscow, Nedra Publ., 1990. pp. 424-427.

17. Kuznetsov V.G. Fatsii i fatsialny analiz v neftegazovoy geologi [Facies and facies analysis in oil and gas geology]. Moscow, Pub- lishing Center of the Russian State University of Oil and Gas named after I.M. Gubkin, 2012. 244 p.

18. Sloss L.A., Crumbain V.K., Daples E.V. Kompleksny fatsialny analiz [Complex facies analysis]. Sedimentary facies in geological history. Moscow, Nedra Publ., 1953. 289 p.

19. Hallem E. Interpretatsiya fatsiy $i$ stratigraficheskaya posledovatelnost [Interpretation of facies and stratigraphic sequence]. Moscow, Mir Publ., 1983. 328 p.

20. Olneva T., Ovechkina V., Zhukovskaya E. Object-oriented geoseismic analysis: ways and examples. XVII Serbian geological congress. Book of Abstracts. Serbia, 2018. pp. 707-713.

21. Linari V., Santiago M., Pastore C., Azbel K., Poupon M. Seismic facies analysis based on 3D multiattribute volume classification, La Palma Field, Maracaibo, Venezuela. The Leading Edge, 2003, pp. $32-36$

22. Davies D.K., Vessell R.K. Flow unit characterization of a shallow shelf carbonate reservoir: North Robinson Unit, West Texas. $10^{\text {th }}$ Symposium on Improved Oil Recovery. Tulsa, 1996. pp. 21-24.

Received: 9 June 2021.

\section{Information about the authors}

Kristina Yu. Chuchalina, master student, National Research Tomsk Polytechnic University.

Mikhail O. Korovin, Cand. Sc., associate professor, National Research Tomsk Polytechnic University. 